education to general social workers and OTs through training, joint working and advice to increase knowledge.

Outcomes It has been helpful in dispelling myths and fears around working with people at the end of their lives and promoting advance care planning within the context of social care. This approach ultimately reaches greater numbers of services users and improves the quality of end of life support to people across the county.

\section{P-188 CO-ORDINATION OF END OF LIFE CARE - A SUCCESSFUL COLLABORATION ACROSS SERVICE BOUNDARIES}

${ }^{1}$ Alison Moorey, ${ }^{2}$ Hugh Lowson. 'St Wiffrid's Hospice, Chichester, UK; ${ }^{2}$ St Barnabas House, Worthing, UK

\subsection{6/bmispcare-2017-hospice.213}

Background Collaborative End of Life Care improvement across a Clinical Commissioning Group had been supported by two hospices part funding the CCG's Project Lead. Serving one of the oldest populations in the UK, with people over 85 being $10 \%$ more likely to have an acute admission ending in death, a consistent approach, strategy and pathway for end of life care were needed.

Aims To develop a centralised, single point of access for patients, their loved ones and carers that would coordinate care, provide advice and help people to reach the most appropriate care and support. The service aims to reduce unscheduled admissions to hospital at end of life, enable more people to die in their preferred place and improve communication and co-ordination between all care providers by the creation of a locality electronic end-of- life-care register.

Method The Community and Acute Trusts worked with three specialist palliative care (SPC) providers including the two hospices to develop a business case for the Collaborative EoLC Hub; this was approved and funded by the CCG. The Community Trust established the co-ordination centre and the three SPC providers are sub- contracted to deliver specialist palliative care advice 24 hours a day, seven days a week. The SPC providers operate a shared on-call rota for clinical nurse specialists and consultants, thereby maximising opportunities to share resources.

Results The co-ordination centre was launched in October 2016, ensuring full engagement with the local health and social care community and the public. Over 600 people are registered but earlier identification of people during the last year of their lives requires more work across the whole health economy.

Conclusions Through collaboration, hospices can deliver solutions to enable CCGs to improve end of life care across their communities and reduce inappropriate admissions to hospital at end of life.

\section{P-189 HOSPICES WORKING WITH COMMISSIONERS - MUTUALLY BENEFICIAL OR A NECESSARY EVIL?}

Heather Palin, Derek Willis. Severn Hospice, Shrewsbury, UK

10.1136/bmjspcare-2017-hospice.214
Background Hospices' value within the third sector is in their specific strategic organisational capabilities. It could be argued that this potential is unrecognised and untapped. The specialist nature of the services that hospices provide and their financial independence and freedom to develop and invest in services place them in a strong position to influence NHS commissioning of services. This study uses the VRIN model to assess the organisation's resources and to demonstrate the hospice's specific strategic capabilities. (Barney \& Hesterley, 2010). This study demonstrates how one hospice has successfully challenged commissioning intentions and evidenced a counter proposal which resulted in the funding and delivery of an enhanced Hospice at Home service.

Aim To prove that increased provision of spells of Hospice at Homecare 24/7 would improve care and support the choice to be cared for and die at home and reduce hospital admissions.

To demonstrate that patients who fit the criteria for Hospice at Home also fit the criteria for $\mathrm{CHC}$ funding and secure that funding for the expansion of service.

Method Through semi-structured interviews we set out to evidence the true gaps in community palliative and end of life care and the approach to commissioning hospice services.

Scoping of the views of the below:

Phase 1 - Local GPs, community nurses and community.

Phase 2 - Commissioners from 2 CCGs

Phase 3 - Wider group of hospice directors (Survey Monkey)

Results

- Counter proposal accepted

- Joint funding of Proof of Concept

- Increased numbers of patients supported at home. Hospital admissions avoided

- Engagement of $\mathrm{CHC}$ and funding agreed.

Conclusion This study demonstrates the potential of hospice strategic organisational capabilities and the value of good relationships with commissioners that place hospices as equal, influential partners within a struggling economic and healthcare environment. This study demonstrates how one hospice has successfully challenged commissioning intentions and evidenced a counter proposal resulting in the funding and delivery of an enhanced Hospice at Home service.

\section{P-190 INVITING THE STRANGER INTO OUR MIDST - A POSITIVE EXPERIENCE BASING A COMMISSIONER IN THE HOSPICE}

${ }^{1}$ Claire Cardy, ${ }^{2}$ Anna Willson. ${ }^{~}$ ellenor Gravesend, UK; ${ }^{2}$ Dartford, Gravesham and Swanley Clinical Commissioning Group, Gravesend, UK

10.1136/bmjspcare-2017-hospice.215

Background The role of commissioning is increasingly important (NHS England: NHS Commissioning online) but can be daunting. Hospices need to find ways to embrace this in order to navigate and improve outcomes in delivering care (NHS England: NHS Commissioning online). Achieving end of life wishes for more people requires transformational change. It is necessary to be innovative and radical, adopting approaches which enable true collaboration (NHS England: Partnerships 
and Relationships online). Working closely with local NHS commissioners ensures that services meet the needs of the local population and provides opportunities to influence development of healthcare services (NHS England: NHS Commissioning online).

Aims Effectively engage with our local CCG Commissioner to create and maintain robust relationships ensuring palliative and end of life care remains a CCG priority.

Methods By reaching out to our lead commissioner we established a more cohesive working relationship, in line with our organisation's values. Our open and honest approach was well received, as was our ability to adapt to an ever-changing healthcare landscape. The commissioner works from the hospice regularly and is on first-name terms with many staff there. Communication with the CCG has vastly improved and the hospice is more widely recognised as the experts in palliative/end of life care.

Results We have been formally recognised by the CCG for our progress over recent years and were asked to collaborate with the lead commissioner to jointly design and deliver an innovative pilot to support patients' preferences at end of life. We received a significant investment from the CCG to support this, and produce monthly KPIs to evidence outcomes and improvement.

Conclusions Having an open and honest relationship with the commissioner has helped us to grow and expand hospice services. Embedding the commissioner within the hospice has helped to place palliative and end of life care firmly at the heart of the commissioning agenda. This hugely positive relationship has ultimately benefitted patient care.

\section{P-191 IN-PATIENT CARE BEING MIRRORED INTO THE COMMUNITY}

Helen Chapman. Isabel Hospice, Welwyn Garden City, UK

\subsection{6/bmispcare-2017-hospice.216}

Background In November 2016 the in-patient unit (IPU) was temporarily closed and relocated to a nursing home to allow essential demolition work. This meant a reduction from 12 to 5 IPU beds. An Enhanced Hospice at Home (EHAH) service was developed to mirror the care we deliver in IPU and support the reduction in beds.

Aim Our organisation wanted to ensure that patients' needs and wishes continued to be met. To enable this, the service supports four patients in their own home environment for end of life care or complex symptom control issues. It is enabling us to bring our in-patient care out into the community.

Methods A team of experienced registered nurses and health care assistants offer up to four visits a day to provide personal care, symptom management and emotional support. Specialist hospice doctors provide daily visits depending on the patient's clinical needs. Care in the community still involves our wider multidisciplinary team including therapists, family support and benefit advice.

Results During the project data has shown 93\% of patients' PPDs that have been home have been met. Combined IPU and EHAH admissions are higher than previous IPU admissions alone. Staff costs have been unchanged by splitting the service.
Feedback Includes ' $I$ felt the team were excellent and it was obvious they were very experienced as they knew exactly how to advise myself and my brother with all aspect of our mother's care.'

'My family felt the care we received was invaluable, it enabled my husband to pass from this world with dignity. It would be wonderful to think that all people could receive this special care in the last days of their lives.'

Conclusion This EHAH has not only helped us provide holistic specialist care to our patients and families but it has also given us the opportunity to build working relationships with GPs and district nurses and be able to share our knowledge and skills.

\section{P-192 TAKING INPATIENT UNIT LEVEL CARE INTO THE HOME: AUTO-ETHNOGRAPHIC REFLECTIONS OF TWO HOSPICE DOCTORS}

H Lucy Thomas, Helen Cooper. Isabel Hospice, Welwyn Garden City, UK

\subsection{6/bmjspcare-2017-hospice.217}

Background In November 2016, building work required us to temporarily reduce the number of our hospice inpatient beds and modify our model of care. We transitioned from having a 12-bed inpatient unit (IPU), to five inpatient beds complemented by four 'enhanced hospice at home' beds providing inpatient-level care to end of life patients with complex needs in their own homes. This included providing up to one medical home visit a day as part of a multidisciplinary team.

Aim In this presentation, we reflect on the impact on our doctoring role of shifting the location of complex end-of-life care from the professional setting to the intimacy of the patient's home.

Methods We used an auto-ethnographic (Chang, 2016) approach to create and analyse written reflections on caring for six patients in the IPU and enhanced hospice at home setting. Based on our analyses, we will present our findings as an illustrative story of caring for one patient and their family. Results We identified four key themes: Fulfilling the promise to provide continuity of care (Leadership Alliance for the Care of Dying People, 2014): 'We'll be there for you until the end [and I mean it].' Dissolving professional boundaries within the multidisciplinary team (Hospice UK, 2015): 'Working together, side by side.' Supporting rather than supplanting existing care (Janssen \& MacLeod, 2012): 'Thank you for helping us care for him.' Shifting the boundaries between care-giver and care-receiver (Janssen \& MacLeod, 2012): 'Would you like a cup of tea doctor? You must find it difficult dealing with all this loss ....'

Conclusions Changing location from a professional setting in which we deliver care, to a home setting into which we are invited as co-carers has the potential to redefine our relationships with our patients, their families and our colleagues. It can enable us to support, rather than supplant reciprocal caring relationships (Janssen \& MacLeod, 2012), embrace national palliative care initiatives (Leadership Alliance for the Care of Dying People, 2014; Thomas et al., 2016), and through increased job satisfaction build our professional resilience (Hospice UK, 2015). 